\title{
Transmission of SARS-CoV-2 infection mother to the newborn
}

\author{
Bonifacio Caballero $^{1 *}$, Daniel Caballero ${ }^{2}$ \\ ${ }^{1}$ Obstetric and Perinatal Care Division, Medical Care Unit, Social Security Mexican Institute (IMSS), Mexico City, \\ Mexico \\ ${ }^{2}$ Faculty of Higher Studies (FES) Zaragoza, National Autonomous University of Mexico (UNAM), Mexico City, \\ Mexico
}

Received: 07 August 2020

Revised: 27 August 2020

Accepted: 28 August 2020

\section{*Correspondence:}

Bonifacio Caballero,

E-mail: bonicaballero1@gmail.com

Copyright: () the author(s), publisher and licensee Medip Academy. This is an open-access article distributed under the terms of the Creative Commons Attribution Non-Commercial License, which permits unrestricted non-commercial use, distribution, and reproduction in any medium, provided the original work is properly cited.

\begin{abstract}
The emergence of the new corona virus infection that occurred in Wuhan, the capital city of China's Hubei province in December 2019 initially labeled 2019-nCoV and later named SARS-CoV-2, has spread in several countries around the world and subsequently raised concerns about the possibility of vertical transmission from the mother to the fetus, producing its disease named COVID-19. Around 12 articles about pregnant women infected with COVID-19 and their newborns have been published between February 10 and April 4, 2020. So far, there are few reports on newborns. There is currently evidence of vertical transmission from pregnant women with COVID-19 infection during the third trimester. The results of this report suggest that currently there is evidence of intrauterine infection caused by vertical transmission in women who develop COVID-19 pneumonia and die in late pregnancy. However, most of these newborns have been asymptomatic or mildly symptomatic, but as the outbreak and information are changing rapidly, it is recommended to continue to check for updates.
\end{abstract}

Keywords: COVID-19, Newborns, Pregnancy, Vertical transmission, SARS-CoV-2

\section{INTRODUCTION}

The coronavirus is an RNA virus and falls into the virus family Corona viridae, order Nidovirales. It is widely found in humans, mammals, and birds and can cause infections of the respiratory tract, gastrointestinal system, and nervous system. The SARS-CoV-2 virus is transmitted mainly via respiratory droplets and/or close contact, human-to-human transmission and family clustering have been reported.

In December 2019, a novel coronavirus, tentatively named as 2019 novel coronavirus (2019-nCoV), was identified in patients with new viral pneumonia as the disease broke out in Wuhan. The emerging SARS-CoV2, a beta coronavirus, can cause COVID-19, officially named by the World Health Organization (WHO) on February 11, 2020. ${ }^{1}$
The clinical symptoms caused by the infection are extremely similar to those of severe acute respiratory syndrome (SARS). ${ }^{2}$

The pregnant women are at a particularly high risk of SARS-CoV-2 infection because they are in a special state of immune tolerance. Reports of pregnant women with severe clinical conditions requiring ICU admission and mechanical ventilation are significantly less common compared to the previous two CoV infections (MERS and SARS) which caused a mortality rate in pregnant women that ranged from $25 \%$ to $30 \% .^{3-15}$

Evidence of vertical intrauterine transmission should be evaluated by testing for the presence of SARS-CoV-2 in swab samples. Both in maternal and neonatal swab samples following WHO guidelines for real-time quantitative chain reaction of polymerase (RT-PCR). ${ }^{16,17}$ 


\section{REVIEW}

Infected or suspected mothers should be carefully monitored before and after delivery. Previously published studies have demonstrated that pregnant women with SARS wereassociated with a higher prevalence of harmful maternal and neonatal side effects including disseminated intravascular coagulopathy, spontaneous abortion, preterm birth, intrauterine growth restriction, and the need of the newborn to be admitted to the NICU. ${ }^{18}$

More importantly, it should be emphasized that there are no specific clinical symptoms in newborns, and therefore there is not clinical evidence of the damage vertical transmission can cause, particularly when COVID-19 infection occurs later in pregnancy.

Some studies, evaluating both caesarean and normal vaginal delivery in mothers with COVID-19, showed that neither type of delivery affected their newborns and all of the studied newborns were negative for COVID-19 infection. ${ }^{19,20}$

Based on the information, COVID-19 cannot be considered as an indication for caesarean delivery and therefore the timing and mode of delivery should be individualized according to clinical maternal conditions or obstetric factors, as usual, and not on COVID-19 infection alone, and the decision should involve a multidisciplinary team including maternal-fetal doctors, neonatologists, anesthesiologists and infectious disease specialists.

It is recommended that all newborns with laboratory confirmed positive tests for SARS-CoV-2 are admitted to the NICU.

The efficacy of antiviral drugs in neonatal age is uncertain at the moment; antimicrobial agents are only useful if bacterial infections are suspected or confirmed.

If newborns have respiratory distress syndrome, high doses of surfactant agent should be administered; nitric oxide inhalation and high-frequency oscillatory ventilation should be considered. In critically ill newborns, intravenous administration of glucocorticoids or immunoglobulinsmay also be considered. ${ }^{21,22}$

Mother-to-child transmission of respiratory viruses mainly occurs through close contact, transmission via droplets (among caregivers, family members, and family visitors), hospital-acquired infections, and exposure to sources of infection in public places.

There is a report of a newborn infected with SARS-CoV2. However, it was possible to document that the transmission occurred horizontally. ${ }^{23}$
The term "vertical transmission" refers to the spread of a pathogen from mother to baby during the period before and after birth. Specifically, it includes transmission via germ cells or placental blood during pregnancy, via the birth canal during labor and delivery.

Shek and Wong found no evidence of perinatal infection among infants born to mothers who developed SARS infection during pregnancy. ${ }^{11,24}$

There are several reports with evidence that the SARSCoV-2 virus can be transmitted intrauterine or transplacentally from infected pregnant women to their fetuses that have identified the presence of IgM and IgG antibodies in neonates born from women with COVID-19 disease. While in other reports, they identified SARSCoV-2 RNA in nasopharyngeal swabs although in a low proportion of the studied newborns. ${ }^{25-28}$

The institution where the first author works, the Mexican Social Security Institute (InstitutoMexicanodelSeguro Social, IMSS) provides social security to more than $50 \%$ of the mexican population.

The number of women in the age range from 15 to 44 years in Mexico is 30,651, as of July01, data calculated by the Department of Economic and Social Affairs, Population Division of the United Nations (2019). ${ }^{29}$

The IMSS accounts for almost $50 \%$ of all public sector births in the country. In 2019,400,156 births were registered; of these, $10.3 \%(41,123)$ were premature under 37 weeks of gestational age and 7,654 (1.9\%) weighed less than $1500 \mathrm{~g}$.

In Mexico,as ofAugust 02, there have been 8,931 cases of women with pregnancy/puerperium being monitored for COVID-19 infection. 39.7\% $(n=3,546)$ have tested positive for COVID-19, of which 97 have died, registering a case fatality rate of $2.7 \%$ and the ratio of maternal death for COVID-19 of 7.4 x 100,000 live births. This represents $18.7 \%$ of reported maternal deaths. $25 \%(n=25)$ of these occurred in IMSS hospitals, in the ICU and were all intubated. There have also been 3,694 notified and registered newbornsof which $20.4 \%$ $(n=755)$ were positive to COVID-19. ${ }^{30}$

Recently Penfield et al. studied a group of 32 pregnant women infected with COVID-19, 11 of whom had samples of placental swabs or membranes, which were searchedusing RT-PCR and turned out positive for SARS-CoV-2. The placental swabs were taken from the amniotic surface after cleaning the surface of maternal blood (RT-PCR of placental sample), the membrane swabs, which were obtained from between the amnion and the chorion after manual separation of the membranes (RT-PCR of membrane sample). The origin of the SARS-CoV-2 RNA detected in this study was not explained. 
The sample for RT-PCR in newborns was taken with nasopharyngeal swabs between days one and five of extrauterine life. However, only three of the 11 infants had positive results. And none developed symptoms of COVID-19. Newborns from that study were born both vaginally and by cesarean section. ${ }^{31}$

Since the first birth occurred in the IMSS in April 03 of this year, of a newborn son of a mother who developed pneumonia and died infected with SARS-CoV-2, as ofAugust 03 there have been 25 cases of maternal deaths whose newborns survived (Daily registry of Maternal Deaths of the Division of Obstetric and Perinatal Care).

These results are similar to those described by Penfield in her studio.

However, in the cases reported as part of this review, the maternal status of COVID-19 of the 25 women was critical and they finally died in the ICU due to multiorgan failure.

The sample for RT-PCR in the newborns was taken with nasopharyngeal swabs between day one and five of extrauterine life. However, only two of the 25 infants had positive results and none developed symptoms of COVID-19. No swabs were taken for placental sample RT-PCR or membrane sample RT-PCR in any of the 25 women's cases at the resolution of pregnancy.

Vivanti et al. reported the transplacental transmission of SARS-CoV-2 in a neonate born from a mother that got infected in the last trimester which presented with neurological manifestations, similar to those described in adult patients. ${ }^{32}$

\section{CONCLUSION}

In summary, the presence of viral RNA in the placenta and membrane samples by RT-PCR at delivery indicates the need for further research on the possibility of vertical transmission and the use of multiple test methods for neonates after birth, while the origin of the RNA maternal or fetal still remains unclear.

We consider, based on the available information at the moment, that performing the nasopharyngeal test immediately after delivery may not be the ideal approach to assess vertical transmission.

Given that the evidence is still insufficient regarding optimal perinatal care and there are no definitive guidelines available, the route of birth, the need for mother-newborn separation, and the benefits of breastfeeding should be individualized in each case.

Although there were no clinical signs in newborns, the findings indicate the possibility of intrapartum viral exposure. It is necessary to have the analysis of more cases to determine this fact.
This review reflects current knowledge about neonatal SARS-CoV-2 infection and vertical transmission in women who develop severe COVID-19 pneumonia and die in late pregnancy; however, it has not been studied whether SARS-CoV-2 infection in the mother could cause alterations in organogenesis and fetal development, but as the outbreak and information change rapidly, we recommend to follow up these cases until the end of the early childhood to look for the possible health implications that this disease has on them.

Funding: No funding sources

Conflict of interest: None declared

Ethical approval: Not required

\section{REFERENCES}

1. World Health Organization. Naming the coronavirus disease (COVID-2019) and the virus that causes it. Available at: https://www.who.int/emergencies/ diseases/novelcoronavirus2019/technicalguidance/n aming-the-coronavirus-disease-(covid-2019)-andthe-virus-that-causes-it Accessed 03 May 2020.

2. World Health Organization. Clinical management of severe acute respiratory infection when novel coronavirus (nCoV) infection is suspected. Interim guidance. Available at: https://www.who.int/docs/default-source/coronaviruse/clinicalmanagementof-novel-cov.pdf Accessed 12 January 2020.

3. Alfaraj H, Tawfiq A, Memish A. Middle East Respiratory Syndrome Coronavirus (MERS-CoV) infection during pregnancy: Report of two cases \& review of the literature. J Microbiol Immunol Infect. 2019;52:501-3.

4. Jeong Y, Sung I, Sung H, Ahn Y, Kang S, Chang S, et al. MERS-CoV infection in a Pregnant Woman in Korea. J Korean Med Sci. 2017;32:1717-20.

5. Alserehi H, Wali G, Alshukairi A, Alraddadi B. Impact of Middle East Respiratory Syndrome coronavirus (MERS-CoV) on pregnancy and perinatal outcome. BMC Infect Dis 2016;16:105.

6. Assiri A, Abedi R, Al Masri M, Saeed B, Gerber S, Watson T. Middle East Respiratory Syndrome Coronavirus Infection During Pregnancy: a Report of 5 Cases From Saudi Arabia. Clin Infect Dis. 2016;63:951-3.

7. Malik A, Masry M, Ravi M, Sayed F. Middle East Respiratory Syndrome Coronavirus during Pregnancy, Abu Dhabi, United Arab Emirates, 2013. Emerg Infect Dis. 2016; 22:515-7.

8. Park H, Kim R, Choi H, Sung H, Kim H. Emergency cesarean section in an epidemic of the Middle East respiratory syndrome: a case report. Korean J Anesthesiol. 2016;69:287-91.

9. Payne C, Iblan I, Alqasrawi S, Nsour A, Rha B, Tohme A, et al. Stillbirth during infection with Middle East respiratory syndrome coronavirus. J Infect Dis. 2014;209:1870-2. 
10. Yudin H, Steele M, Sgro D, Lea E, Kopplin P, Gough A. Severe acute respiratory syndrome in pregnancy. Obstet Gynecol. 2005;105:124-7.

11. Wong F, Chow M, Leung N, Ng F, Ng K, Sheket $\mathrm{C}$, et al. Pregnancy and perinatal outcomes of women with severe acute respiratory syndrome. Am J Obstet Gynecol. 2004;191:292-7.

12. Lam M, Wong F, Leung N, Chow M, Yu C, Wonget $\mathrm{Y}$, et al. A case-controlled study comparing clinical course and outcomes of pregnant and non-pregnant women with severe acute respiratory syndrome. Int J Obstre. Gynaeco. 2004;111:771-4.

13. Robertson A, Lowther A, Birch T, Tan h, Sorhage F, Stockman L, et al. SARS and pregnancy: a case report. Emerg Infect Dis. 2004;10:345-8.

14. Schneider E, Duncan D, Reiken M, Perry R, Messick J, Sheedy C, et al. SARS in pregnancy: this case study explores the first documented infection in the U.S.A. WHONN Lifelines 2004;8:122-8.

15. Stockman J, Lowther A, Coy K, Saw J, Parashar D. SARS during pregnancy, United States. Emerg Infect Dis. 2004;10:1689-90.

16. World Health Organization. Laboratory testing for 2019 novel coronavirus (2019-nCoV) in suspected human cases. Interim guidance, 2020. Available at: https://www.who.int/publications-detail/laboratorytesting-for-2019-novel-coronavirus-in-suspectedhuman-cases-20200117 Accessed on 4 May 2020.

17. Corman M, Landt O, Kaiser M, Molenkamp R, Meijer A, Chu K,et al. Detection of 2019 novel coronavirus (2019-nCoV) by real-time RT-PCR. Euro Surveill 2020;25:2000045.

18. Liu D, Li L, Xin W, Zheng D, Wang J, Yanget L, et al. Pregnancy and Perinatal Outcomes of Women with COVID-19 Pneumonia: A Preliminary Analysis. Available at: SSRN 3548758. 2020.

19. Chen H, Guo J, Wang C, Luo F, Yu X, Zhang W, et al. Clinical characteristics and intrauterine vertical transmission potential of COVID-19 infection in nine pregnant women: a retrospective review of medical records. Lancet. 2020;395:809-15.

20. Panahi L, Amiri M, Pouy S. Risks of Novel Coronavirus Disease (COVID-19) in Pregnancy; a Narrative Review. Arch Acad Emerg Med. 2020;8(1):e34.

21. Wang J, Qi H, Bao L, Li F, Shi Y. National Clinical Research Center for Child Health and Wang J, Qi H, Bao L, Li F, Shi Y. A contingency plan for the management of the 2019 novel coronavirus outbreak in neonatal intensive care units. Lancet Child \& Adoles. Heal. 2020;4(4):258-9.

22. Caballero B, Méndez A, Caballero D. Varicellazoster infection in the newborn: a case. Gaceta Médica de Bilbao. 2016;113(1):28-31.
23. Díaz A, Maestro L, Pumarega T, Antón F, Alonso R. Primer caso de infección neonatal por SARSCoV-2 en España. In Anales De Pediatria 2020;92(4): 237.

24. Shek C, Ng C, Fung P, Cheng T, Chan S, Peiris S, et al. Infants born to mothers with severe acute respiratory syndrome. Pedia. 2003;112:e254.

25. Zeng H, Xu C, Fan J, Tang Y, Deng Q, Zhang W, et al. Antibodies in infants born to mothers with COVID-19 pneumonia. J American Med Asso. 2020.

26. Dong L, Tian J, He S, Zhu C, Wang J, Liu C, et al. Possible vertical transmission of SARSCoV-2 from an infected mother to her newborn. J American Med Asso. 2020.

27. Patanè L, Morotti D, Giunta R, Sigismondi C, Piccoli G, Frigerio L, et al. Vertical transmission of COVID-19: SARS-CoV-2 RNA on the fetal side of the placenta in pregnancies with COVID-19 positive mothers and neonates at birth. American J Obste Gyneco. 2020.

28. Kirtsman M, Diambomba Y, Poutanen M, Malinowski K, Vlachodimitropoulou E, Parkset T, et al. Probable congenital SARS-CoV-2 infection in a neonate born to a woman with active SARS-CoV2 infection. Canadian Med Asso J. 2020;192(24):647-50.

29. United Nations, Department of Economic and Social Affairs, Population Division (2019). World Population Prospects 2019, Online Edition.Rev. Available at: https://www.un.org/en/development/ desa/population/index.asp Accessed on 7 May 2020.

30. Salud S. The weekly epidemiological report of pregnant and puerperal women studied, on suspicion of COVID-19. Available at: https://www.gob.mx/salud/documentos/informesepidemiologicos-de-embarazadas-y-puerperasestudiadas-ante-sospecha-de-covid-19. Accessed on 03 August 2020.

31. Penfield A, Brubaker G, Limaye A, Lighter J, Ratner A, Thomas M, et al. Detection of severe acute respiratory syndrome corona virus 2 in placental and fetal membrane samples. American J Obste Gyneco 2020;100133.

32. Vivanti A, Fellous V, Prevot S, Zupan V, Suffee C, Cao D, et al. Transplacental transmission of SARSCoV-2 infection. Nat Commun. 2020;11:3572.

Cite this article as: Caballero B, Caballero D. Transmi-ssion of SARS-CoV-2 infection mother to the new born. Int J Contemp Pediatr 2020;7:2086-9. 